\title{
Belief in God and Psychological Distress: Is It the Belief or Certainty of the Belief?
}

\author{
Zachary E. Magin ${ }^{1}\left(\mathbb{D}\right.$, Adam B. David $^{1}\left(\mathbb{D}\right.$, Lauren M. Carney ${ }^{1}$, Crystal L. Park $^{1, *}\left(\mathbb{C}\right.$, Ian A. Gutierrez ${ }^{1,+}(\mathbb{D}$ \\ and Login S. George ${ }^{2}$ \\ 1 Department of Psychological Sciences, University of Connecticut, Storrs, CT 06269, USA; \\ zachary.magin@uconn.edu (Z.E.M.); adam.david@uconn.edu (A.B.D.); lauren.m.carney@uconn.edu (L.M.C.); \\ ian.gutierrez.phd@gmail.com (I.A.G.) \\ 2 Institute for Health, Health Care Policy and Aging Research, School of Nursing, Rutgers University, \\ New Brunswick, NJ 08901, USA; login.s.george@gmail.com \\ * Correspondence: crystal.park@uconn.edu \\ † Current address: Walter Reed Army Institute of Research, Silver Spring, MD 20910, USA.
}

Citation: Magin, Zachary E., Adam B. David, Lauren M. Carney, Crystal L. Park, Ian A. Gutierrez, and Login S. George. 2021. Belief in God and Psychological Distress: Is It the Belief or Certainty of the Belief?. Religions 12: 757. https://doi.org/10.3390/ rel12090757

Academic Editor: Hans Zollner

Received: 2 July 2021

Accepted: 2 September 2021

Published: 13 September 2021

Publisher's Note: MDPI stays neutral with regard to jurisdictional claims in published maps and institutional affiliations.

Copyright: (c) 2021 by the authors. Licensee MDPI, Basel, Switzerland. This article is an open access article distributed under the terms and conditions of the Creative Commons Attribution (CC BY) license (https:// creativecommons.org/licenses/by/ $4.0 /)$.

\begin{abstract}
Research on the relationship between belief in God and mental health is scarce and often limited to comparing group differences in mental health across various self-reported religious identities (e.g., atheists, agnostics, believers). To advance this work, we focused on how the extent of belief in God related to three indices of psychological distress (depression, anxiety, and stress) in a sample of undergraduate students $(\mathrm{N}=632)$ with a variety of religious identities. We used a model comparison approach to evaluate both linear and curvilinear relationships between belief in God and psychological distress and tested potential mediating pathways for linear relationships. The findings revealed that belief in God was negatively linearly related to depression; this relationship was fully mediated by meaning in life, feeling comforted by God, positive religious coping, positive reappraisal, and substance use coping. In contrast, belief in God was curvilinearly related to anxiety but unrelated to stress. These results suggest that both strength and certainty of the belief in God may be important in understanding religion's relationship with psychological distress.
\end{abstract}

Keywords: God; depression; anxiety; stress; atheism; curvilinear; certainty

\section{Introduction}

Theoretical work on the role of religion in mental health is long-standing, with theorists such as Marx (1970) proclaiming religion to be "the opium of the people" (p. 1), and Freud [1907] (Freud [1907] 1959) describing religious practices as "obsessive actions" (p. 117). In contrast, William James [1902] (James [1902] 1958) described the potential for healthy expressions of religion that may be linked with greater well-being and health. Along that same line of thinking, recent empirical research has demonstrated consistent associations between higher levels of religiosity and better mental health (AbdAleati et al. 2016; Moreira-Almeida et al. 2006; Park et al. 2019). For example, religiosity is associated with reduced risk/severity of depression (Bush et al. 2012; Rasic et al. 2011), anxiety (Sternthal et al. 2010), substance misuse (Moscati and Mezuk 2014), and post-traumatic stress symptoms (Tran et al. 2012). Considered as a unidimensional construct, then, one might conclude that religiosity is generally beneficial for psychological functioning. However, such a view obscures the complexity of religiosity; in fact, religiosity comprises multiple dimensions, each of which has its own relationship to mental health (Ashouri et al. 2016).

One critical dimension of religiosity is belief in God (Fetzer Institute/National Institute on Aging Working Group 1999). Surprisingly, however, this central aspect of religiosity is rarely examined in relation to mental health (Bosco-Ruggiero 2020; Wilkinson and Coleman 2010), and when it is, the findings are difficult to interpret (Silton et al. 2013). Scholars 
have evaluated the relationship between belief in God and mental health by examining differences in mental health among those who self-identify as atheists, agnostics, and religiously affiliated (e.g., Paterson and Francis 2017). Given that self-identified atheists do not believe that God exists, while agnostics are ambivalent or unsure about the existence of God, researching differences between atheists, agnostics, and religiously affiliated individuals has been thought to provide insight into the effects of belief in God. For example, using this approach, one study observed greater anxiety in atheists and agnostics compared to religiously affiliated individuals and individuals who reported no group religious preference (Ashouri et al. 2016).

Yet, few studies have directly tested the relationship between belief in God and mental health. Those that have tend to support a linear model of belief in God and mental health, such that individuals who believe in God have better mental health than individuals who do not believe in God (Koenig 2009). For example, belief in God has been associated with greater reductions in depression and self-harm over the course of cognitive behavioral therapy (Rosmarin et al. 2013). Additionally, a study of patients with congestive heart failure found that greater belief in God was associated with fewer depressive symptoms six months later (Carney et al. 2020).

To the extent that belief in God is linearly and positively related to mental health, it is important to understand how this belief influences mental health (i.e., the mediating variables that explain those relationships). One potential explanation is meaning in life; individuals who believe in God have more meaning in life (Cranney 2013; Steger and Frazier 2005), and meaning in life, in turn, relates to better mental health (Park 2007). Additionally, coping strategies for managing stress affect mental health (e.g., Jiang et al. 2017); those who believe in God may benefit from using more effective strategies such as religious coping (Gall and Guirguis-Younger 2013) and positive reappraisal (Dolcos et al. 2021) that are less likely to be employed by individuals who do not believe in God. Thus, differences in coping styles may account for the relationships between belief in God and mental health. Similarly, those who believe in God may find God to be a source of comfort, which in turn relates to better mental health (Exline et al. 2017). Taken together, these studies suggest that this set of mediating variables may explain the relationship between belief in God and mental health, but these mediational pathways have yet to be tested.

In contrast to the scholarship supporting the linear model of belief in God and mental health, findings from some studies have suggested that certainty of the belief that God exists or certainty of the belief that God does not exist is more pertinent than the belief itself. That is, regardless of the content of the belief, it is the certainty of that belief that influences well-being; uncertainty itself is distressing (McNulty et al. 2004). These studies have found a curvilinear relationship between belief and well-being such that those with greater certainty in their belief-either in the existence of God or the non-existence of God-had higher well-being relative to those who were less certain or doubtful (Galen and Kloet 2011; Krause 2006; Paterson and Francis 2017). By extension, then, the curvilinear model would expect to see a curvilinear relationship between belief in God and mental health, reflecting certainty of the belief.

Additionally, a number of confounding variables preclude a clear understanding of the relationship between belief in God and mental health. One noteworthy confounder is the influence that stigmatization may have on non-believers' mental health (Doane and Elliott 2015). Negative stereotypes of atheists held by the American public include being rebellious, immoral, judgmental, cynical, hedonistic, and lacking in moral acuity (Harper 2007). Furthermore, one study found that $95 \%$ of atheists reported experiencing some form of discrimination (Hammer et al. 2012). In a national sample of atheists, perceived discrimination was negatively related to life satisfaction and self-esteem, and positively related to negative affect (Doane et al. 2014). These results indicate that atheists could have a lower sense of well-being due to stigmatization and discrimination.

Furthermore, the current approach of categorizing individuals by their self-reported group identification has notable limitations. By relying on self-reported identification, 
researchers risk underrepresenting atheists due to the abovementioned stigmatization and the negative connotations of atheism (Edgell et al. 2006). Indeed, Gervais and Najle (2018) found that atheism rates are significantly higher than is indicated in self-report surveys and argued that this discrepancy may be due to atheists' hesitancy to label themselves as members of a stigmatized group. Relatedly, survey data also revealed that individuals often indicate an affiliation without having a belief in God (Pew Research Center n.d.). Thus, this inexact correspondence between reported belief in God and reported affiliation may have impacted researchers' ability to reliably study atheists. To accurately understand the relationship between belief in God and mental health, studies are needed that specifically ask participants about their belief in God.

Belief in God might also have distinct relationships with different aspects of psychological distress. Some studies have collapsed across facets of mental health with constructs such as well-being (Schnitker et al. 2017), while other studies that evaluated specific aspects of mental health indicate that belief in God relates to measures of distress in different ways. For example, among 118 individuals reflecting on their prior experience with psychotherapy, atheists reported less distress and improved well-being, while the religious participants reported more benefits in coping and social functioning (Paterson and Francis 2017). Such studies demonstrate the need to evaluate the specific effects of belief in God on different aspects of distress to better understand how belief in God functions in relation to mental health.

Given the inconsistent findings and the potential for confounding variables in previous studies on the relationship between belief in God and mental health, studies are needed that specifically address these limitations. Therefore, the current study aimed to examine the links between belief in God and three distinct domains of psychological distressdepression, anxiety, and stress-and to identify the mediating variables underlying those relationships. Furthermore, the current study also addressed the limitations in the literature in the following ways: (1) rather than relying on a forced-identity choice to indirectly measure belief in God, we directly asked participants about the extent to which they believed in God; (2) given the potential effects of belief in God on distinct aspects of mental health, we measured three different aspects separately; (3) we used a model comparison approach to evaluate both the linear and curvilinear relationships between belief in God and each of the aspects of mental health to examine the issue of certainty versus the content of belief; (4) our college student sample represents a population that generally holds a less stigmatized view of atheists (Bowman et al. 2017), meaning we can more confidently attribute any differences in mental health to belief in God, rather than the impact of the stigma associated with non-belief and atheism.

The first aim of the current study was to evaluate the two competing models on the relationship between belief in God and mental health: the linear model and the curvilinear model. The linear model would suggest that individuals who believe in God would be less depressed, anxious, and stressed than those who do not believe in God, whereas the curvilinear model proposes that the relationship between belief and depression, anxiety, and stress would be non-linear. According to that hypothesis, those who have more certainty would be less depressed, anxious, and stressed than those with less certainty regarding their belief in God. For both theoretical models, we were interested in examining whether these relationships varied by the domain of psychological distress.

The second aim of the study was to identify the potential mediators to explain relationships between belief in God and mental health. Based on prior research, we hypothesized that the following variables would account for any linear relationships observed between belief in God and distress: meaning in life (Park 2007), religious coping (Horning et al. 2011), comfort from God (Exline et al. 2000), positive reappraisal (Dolcos et al. 2021), and substance use to cope (Horning et al. 2011; see Figure 1 for theoretical model). By addressing these aims, the current study advances our understanding of the relationship between belief in God and mental health. 


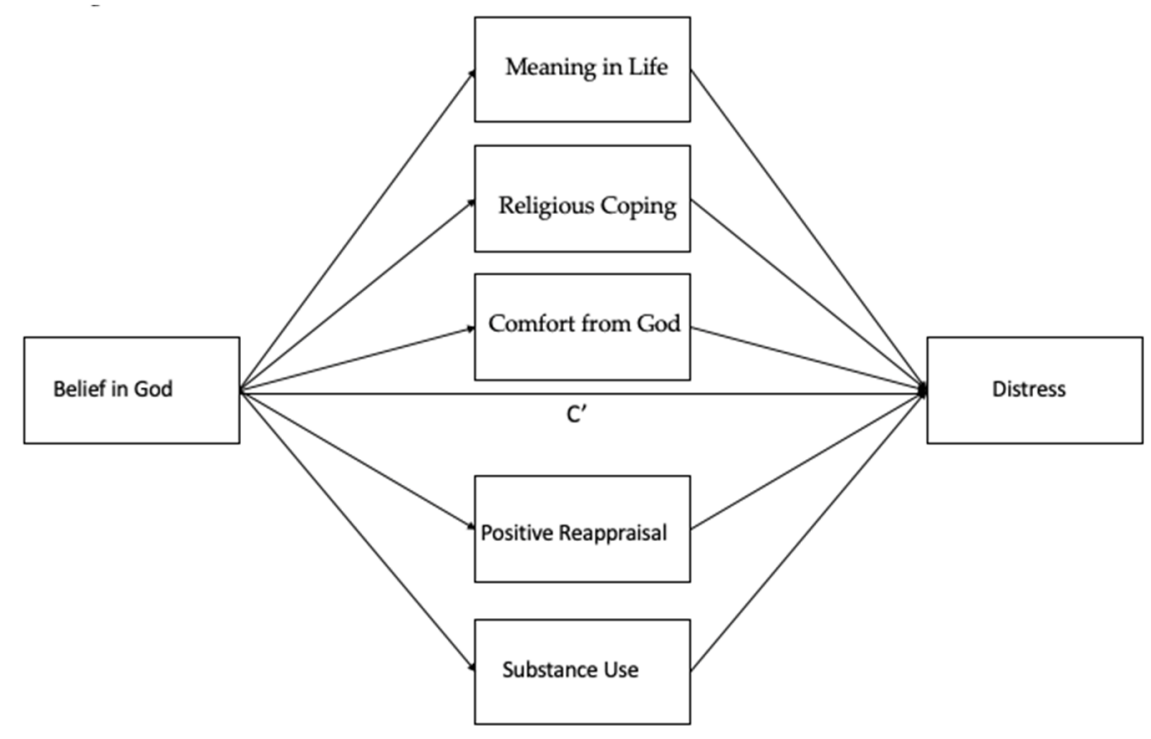

Figure 1. Theoretical model for mediating variables of belief in God and distress.

\section{Materials and Methods}

\subsection{Participants}

The current sample included 632 undergraduate students attending a large public university in the Northeastern United States. Participants were: 62\% White/EuropeanAmerican, 22\% Asian, 11\% Latino, 6\% Black/African American, and 6\% other, between the ages of 18 and 47 (mean $=18.83, \mathrm{SD}=1.68)$. With respect to religious affiliation, the sample was 46\% Christian, 5\% Muslim, 3\% Hindu, 3\% Jewish, 1\% Buddhist, $<1 \%$ Sikh, $<1 \%$ Neo-Pagan/Mystical/Occult, $<1 \%$ Scientologist, and 5\% other religious preference. The remaining portion of the sample (37\%) responded "no religion" to the question of religious preference. To capture responses across the full range of religious beliefs, the current study used pre-screening to include a greater proportion of non-religious individuals.

\subsection{Measures and Procedures}

Participants completed an online survey lasting approximately 30 minutes for research participation course credit. The study was approved by the University of Connecticut Institutional Review Board and was conducted in accordance with ethical research practices.

\subsubsection{Belief in God}

Belief in God was measured with one item from the Rohrbaugh and Jessor Religiosity Scale (Rohrbaugh and Jessor 1975), which asks participants to indicate which of the following five statements comes closest to their belief about God: "I am sure God really exists and that He is active in my life" (5); "Although I sometimes question His existence, I do believe in God and believe He knows of me as a person" (4); "I don't know if there is a personal God, but I do believe in a higher power of some kind" (3); "I don't know if there is a personal God or a higher power of some kind, and I don't know if I ever will" (2); and "I don't believe in a personal God or in a higher power" (1). Statements were coded on a scale from 1 to 5 , such that higher scores represented believing more in a personal God, and lower scores represented believing less in a personal God. Scores closer to the middle of this continuous variable (2-4) represented less certainty of the belief in a personal God than either of the extreme scores (1 and 5).

\subsubsection{Depression, Anxiety, and Stress}

Depression, anxiety, and stress were measured with the Depression, Anxiety, and Stress Scales-21 (DASS-21; Henry and Crawford 2005). The DASS-21 is a 21-item validated measure of three domains of psychological distress: depression, anxiety, and stress. Par- 
ticipants were asked to rate how much each statement applied to them in the past week. Responses were captured with a four-point Likert scale, ranging from "Did not apply to me at all" (0) to "Applied to me very much or most of the time" (3). Scores for each of the subscales were calculated by summing each of the values within the subscales and then multiplying them by two, so that scores could be compared to the DASS- 42 scores. Higher scores on each subscale indicate more distress (greater depression, anxiety, and stress). Internal consistency for the Depression $(\alpha=0.90)$, Anxiety $(\alpha=0.83)$, and Stress $(\alpha=0.86)$ subscales was good.

\subsubsection{Meaning in Life}

Meaning in life was measured with the Presence of Meaning subscale of the Meaning in Life Questionnaire (MLQ; Steger and Frazier 2005). The MLQ Presence of Meaning subscale is a five-item questionnaire that asks participants to rate statements such as, "I have a good sense of what makes my life meaningful" using a seven-point Likert scale, ranging from "Absolutely Untrue" (1) to "Absolutely True" (7). Higher scores indicate high levels of meaning in life. Internal consistency for the Presence of Meaning subscale was good $(\alpha=0.84)$.

\subsubsection{Comfort by God}

The Comfort by God subscale from the Attitude Toward God Scale-9 (ATGS-9; Wood et al. 2010) was used to measure the extent to which participants felt comforted by God. The ATGS-9 Comfort by God subscale asks participants to rate the extent that they currently do or feel statements such as "Feel supported by God" and "Feel nurtured by God" on a scale from "Not at all" (0) to "Extremely" (10). Higher scores on the Comfort scale of the ATGS-9 indicate feeling greater levels of comfort by God. Internal consistency for the Comfort by God subscale was good $(\alpha=0.99)$.

\subsubsection{Positive Religious Coping}

Positive religious coping was measured with the Positive Religious Coping scale of the Brief RCOPE (Pargament et al. 2011). The Brief RCOPE asks participants to indicate how much they use different types of religious coping strategies to manage stressors, such as "Sought God's love and care," and "Focused on religion to stop worrying about my problems." Participants' responses were captured with a four-point Likert scale, ranging from "Not at all" (1) to "A great deal" (4). Higher scores on the Positive Religious Coping subscale indicate a greater frequency of using positive religious coping strategies to manage stressors. Internal consistency for the Positive Religious Coping subscale was good $(\alpha=0.96)$.

\subsubsection{Positive Reappraisal and Substance Use Coping}

The COPE Inventory was used to measure positive reappraisal and substance use in response to stressors. The COPE Inventory asks participants to indicate how frequently they rely on various coping strategies when dealing with stressors. Participants responded using a four-point Likert scale, ranging from "I usually don't do this at all" (1) to "I usually do this a lot" (4). The current study specifically focused on the Positive Reinterpretation and Growth scale to measure positive reappraisal, and the Substance Use scale to measure use of alcohol and other drugs in response to stress. Scores were calculated for each scale by summing the ratings. Higher scores indicated relying more heavily on the given coping strategy in times of stress.

\subsection{Statistical Procedures}

All statistical procedures were conducted using $\mathrm{R}$ version 3.6.3. To determine the best-fitting relationships between belief in God and psychological distress, linear and quadratic models were built with belief in God as the predictor and depression, anxiety, 
and stress as the outcome variables in separate models (the general structure of models represented by Model A and Model B).

$$
\begin{array}{ll}
\hat{Y}=C+B X & \text { Model } A \\
\hat{Y}=C+B_{1} X+B_{2} X^{2} & \text { Model B }
\end{array}
$$

Using analysis of variance, the two models were then compared to determine if they were significantly different from each other. If Model B was significantly different from Model A, then Model B was considered a better-fitting model. If Model A and B were not significantly different, in accordance with the law of parsimony (Vandekerckhove et al. 2015), Model A was identified as the model that best describes the data. This process was repeated for each outcome variable-depression, anxiety, and stress - to determine which model best describes the relationships between belief in God and the three measures of psychological distress. For any linear models identified as the best-fitting model, mediational analyses were conducted using the Lavaan package in R (Rosseel 2012).

\section{Results}

\subsection{Correlations and Descriptive Statistics}

Belief in God was significantly negatively correlated with depression $(r(630)=-0.16$, $p<0.001)$, but not with anxiety $(r(630)=-0.02, p=0.57)$ or stress $(r(630)=-0.04, p=0.36$; see Table 1). Additionally, the correlations between depression and anxiety $(r(630)=0.61$, $p<.001)$, depression and stress $(r(630)=0.70, p<0.001)$, and anxiety and stress $(r(630)=0.75$, $p<0.001)$ suggest that these constructs were strongly related but distinct. The correlations between depression and each of the mediators ranged from small (for positive religious coping, $r(630)=-0.09, p=0.03$ ) to medium (for meaning in life, $r(630)=-0.40, p<0.001$ ). Similar correlations for anxiety and stress were observed with each of the proposed mediating variables, with the exceptions of comfort by God and anxiety $(r(630)=-0.02, p=0.71)$ as well as comfort by God and stress $(r(630)=-0.05, p=0.21)$.

\begin{tabular}{|c|c|c|c|c|c|c|c|c|c|}
\hline & 1 & 2 & 3 & 4 & 5 & 6 & 7 & 8 & 9 \\
\hline 1. Belief in God & 1.00 & & & & & & & & \\
\hline 2. Depression & $-0.16^{* *}$ & 1.00 & & & & & & & \\
\hline 3. Anxiety & -0.02 & $0.61 * *$ & 1.00 & & & & & & \\
\hline 4. Stress & -0.04 & $0.70 * *$ & $0.75^{* *}$ & 1.00 & & & & & \\
\hline 5. Meaning & $0.34^{* *}$ & $-0.40 * *$ & $-0.15^{* *}$ & $-0.16^{* *}$ & 1.00 & & & & \\
\hline 6. Comfort by God & $0.88^{* *}$ & $-0.18^{* *}$ & -0.02 & -0.05 & $0.34 * *$ & 1.00 & & & \\
\hline 7. Positive Religious Coping & $0.76^{* *}$ & $-0.09+$ & $0.09+$ & 0.04 & $0.35^{* *}$ & $0.84^{* *}$ & 1.00 & & \\
\hline 8. Positive Reappraisal & $0.15^{* *}$ & $-0.24 * *$ & $-0.09+$ & $-0.11 *$ & $0.34 * *$ & $.21 * *$ & $0.22 * *$ & 1.00 & \\
\hline 9. Substance Use Coping & $-0.12 *$ & $0.27 * *$ & $0.23^{* *}$ & $0.25^{* *}$ & $-0.16^{* *}$ & $-0.10+$ & -0.04 & $-0.12 *$ & 1.00 \\
\hline$M$ & 2.56 & 8.51 & 8.08 & 11.46 & 21.24 & 25.55 & 14.31 & 11.80 & 5.48 \\
\hline$S D$ & 1.47 & 8.80 & 7.94 & 8.69 & 6.29 & 20.25 & 6.95 & 2.70 & 2.62 \\
\hline Scale Range & $1-5$ & $0-42$ & $0-42$ & $0-42$ & $5-35$ & $0-50$ & $7-28$ & $4-16$ & $4-16$ \\
\hline
\end{tabular}

Table 1. Intercorrelations, Means, and Standard Deviations for Study Variables.

\subsubsection{Belief in God and Depression}

As displayed in Table 2, the model comparisons with analysis of variance revealed that the quadratic model was not significantly different from the linear model of belief in God and depression, suggesting that the linear model best explains the relationship between these two variables. The results revealed a negative relationship between belief in God and depression, such that greater belief in God was associated with lower levels of depression, $B=-0.164, p<0.001$. The mediational analyses revealed that the proposed mediators fully mediated the relationship between belief in God and depression (see Table 3). After accounting for the indirect pathways between belief in God and depression, the relationship between belief in God and depression was no longer significant, $B=0.025$, $p=0.739$. When tested together, belief in God predicted each of the mediating variables 
in the expected directions, and each of the mediating variables predicted depression in the expected direction. The one notable exception was positive religious coping, which was positively associated with depression when accounting for the effects of the other mediating variables, $B=0.286, p<0.001$.

Table 2. Model comparisons to identify best-fitting models between belief in God and depression, anxiety, and stress.

\begin{tabular}{|c|c|c|c|c|}
\hline \multirow{2}{*}{ Variable } & \multirow{2}{*}{$\frac{\text { Model A }}{B_{1}}$} & \multicolumn{2}{|c|}{ Model B } & \multirow{2}{*}{ F } \\
\hline & & $B_{1}$ & $B_{2}$ & \\
\hline Depression & -0.164 & 0.238 & -0.409 & 3.388 \\
\hline Anxiety & -0.023 & 0.482 & -0.513 & 5.208 * \\
\hline Stress & -0.038 & 0.380 & -0.425 & 3.569 \\
\hline
\end{tabular}

Table 3. Mediation for the relationship between belief in God and depression.

\begin{tabular}{|c|c|c|c|c|c|}
\hline Path and Variable & $B$ & SE & $\begin{array}{c}95 \% \\
\text { Lower CI }\end{array}$ & $\begin{array}{c}95 \% \\
\text { Upper CI }\end{array}$ & $p$ \\
\hline \multicolumn{6}{|l|}{ Belief in God to mediators (paths $a$ ) } \\
\hline Meaning in Life & 0.344 & 0.034 & 0.277 & 0.411 & $<0.001$ \\
\hline Comfort by God & 0.880 & 0.007 & 0.866 & 0.894 & $<0.001$ \\
\hline Positive Religious Coping & 0.765 & 0.014 & 0.738 & 0.793 & $<0.001$ \\
\hline Positive Reappraisal & 0.154 & 0.039 & 0.077 & 0.230 & $<0.001$ \\
\hline Substance Use Coping & -0.115 & 0.039 & -0.193 & -0.038 & 0.004 \\
\hline \multicolumn{6}{|l|}{ Mediators to Depression (paths $b$ ) } \\
\hline Meaning in Life & -0.347 & 0.038 & -0.422 & -0.273 & $<0.001$ \\
\hline Comfort by God & -0.282 & 0.088 & -0.453 & -0.100 & 0.001 \\
\hline Positive Religious Coping & 0.286 & 0.065 & 0.158 & 0.413 & $<0.001$ \\
\hline Positive Reappraisal & -0.109 & 0.038 & -0.183 & -0.035 & 0.004 \\
\hline Substance Use Coping & 0.198 & 0.035 & 0.129 & 0.267 & $<0.001$ \\
\hline \multicolumn{6}{|c|}{ Direct effect of Belief in God on Depression (path c) } \\
\hline Belief in God & -0.163 & 0.039 & -0.239 & -0.087 & $<0.001$ \\
\hline \multicolumn{6}{|c|}{$\begin{array}{l}\text { Direct effect of Belief in God on Depression with mediators included } \\
\text { (path } c^{\prime} \text { ) }\end{array}$} \\
\hline Belief in God & 0.025 & 0.075 & -0.122 & 0.172 & 0.739 \\
\hline
\end{tabular}

\subsubsection{Belief in God and Anxiety}

As displayed in Table 2, the model comparisons revealed that a significant curvilinear relationship between belief in God and anxiety best explained the current data, $\mathrm{F}=5.208$, $p=0.023$. Those with a firmer belief or nonbelief in God were less anxious than those who were less sure of their belief in God, $B_{1}=0.482, p=0.019 ; B_{2}=-0.513, p=0.023$ (see Figure 2).

\subsubsection{Belief in God and Stress}

The model comparisons indicated that a linear model best described the relationship between belief in God and stress (see Table 2). However, examining the linear model revealed that there was no detectable relationship between belief in God and stress, $B=-0.038, p=0.343$. 


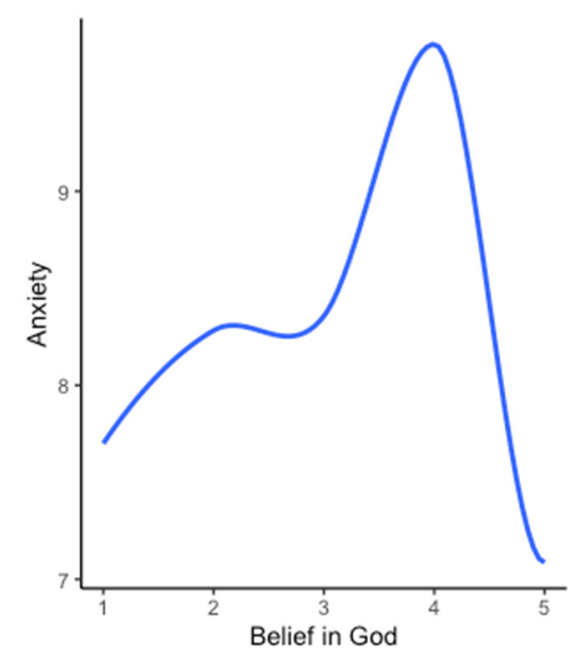

Figure 2. Visual representation of the relationship between belief in God and anxiety. Note: those who had a greater belief in God or disbelief in God reported lower anxiety than those who were unsure about God's existence. There was no statistically significant difference in anxiety between those who firmly believed in God (5) and those who firmly did not believe in God (1), $t(318)=0.658$, $p=0.511$.

\section{Discussion}

The current study builds on previous research on the relationship between belief in God and mental health by explicitly measuring belief in God and depression, anxiety, and stress. Our first aim was to evaluate two competing models on the relationship between belief in God and mental health: the linear model and the curvilinear model. The finding that greater belief in God was inversely associated with depression provides some support for the linear model, indicating that greater belief in God-regardless of the certainty of that belief-may benefit this domain of psychological distress. While other studies have demonstrated relationships between religious beliefs or involvement and depression (Austin and Lennings 1993; Murphy and Fitchett 2009; Ronneberg et al. 2016; Rosmarin et al. 2013), this is the first study to evaluate both linear and curvilinear models for the relationship between belief in God and depression. In support of the linear model, this finding suggests that a higher belief in God may reduce or prevent the risk/severity of depression.

In contrast to the linear relationship observed between belief in God and depression, we observed a curvilinear relationship between belief in God and anxiety. Consistent with Galen and Kloet's (Galen and Kloet 2011) curvilinear hypothesis of religiosity and mental health, the current findings indicate that certainty of the belief may be more relevant for anxiety than the belief itself. The individuals who were less certain about God's existence or non-existence had higher levels of anxiety than the individuals with greater certainty (see Figure 2). Certainty of the belief-regardless of the belief itself-may reduce anxiety (Galen and Kloet 2011). These findings are consistent with certainty in the broader psychological literature, which demonstrates that certainty is robustly associated with lower anxiety (Hirsh et al. 2012).

Surprisingly, the results of the current study suggest that there is no linear or curvilinear relationship between belief in God and stress. The lack of an observed relationship between belief in God and stress may be a function of the measure of stress used. The DASS-21 stress subscale reflects less the global psychological sense of being overwhelmed than the physiological arousal from stress (Park et al. 2021). It may be the case that belief in God reduces one's likelihood of feeling overwhelmed but does not impact one's general physiological arousal, even though it has been shown to relate to the likelihood of reacting to acute provocation (Farias and Newheiser 2019). Future studies are needed to determine 
whether belief in God relates to other types of stress, apart from the physiological signs of stress.

To address the second aim of identifying the mediating variables of belief in God and mental health, five mediating pathways were examined. Because only the depression models suggested a linear relationship, mediation was only tested for depression. The results indicated that the proposed variables fully mediated the relationship between belief in God and depression. These findings suggest that meaning in life, feeling comforted by God, and healthy coping strategies account for most of the variance in the relationship between belief in God and depression. Individuals with a greater belief in God had a greater sense of meaning in life, which in turn was associated with less depression. This finding is consistent with the broader literature showing that meaning in life functions as a mediator of the effect of religiosity on mental health (Park 2007). Additionally, greater belief in God was associated with greater comfort by God, which was negatively related to depression. This finding is not surprising, given that perceiving God as comforting is contingent on the belief that God exists; however, this finding suggests that the comfort itself may act as a resource for believers compared to nonbelievers, which partially explains the finding of less depression among believers. It is also worth noting that, when controlling for the other mediating variables in the model, positive religious coping was associated with greater levels of depression. One interpretation of this finding is that the variance accounted for by the other variables in the model explained most of the benefits of religious coping; when those beneficial aspects of religious coping are removed, the remaining variance in religious coping may be unhelpful. The individuals who believed in God were more likely to use positive reappraisal, which was associated with less depression. Additionally, a higher belief in God was associated with a lower likelihood of using substances to cope, which was also associated with less depression. These healthier coping strategies have been observed in prior studies examining the differences between believers and non-believers (Dolcos et al. 2021; Horning et al. 2011), although this is the first study to identify them as potential mediators for the relationship between belief in God and depression. By demonstrating that these resources fully account for the relationship between belief in God and depression, the current study provides a fuller explanation of how belief in God may reduce depression.

Findings from the current study suggest that there are unique relationships between belief in God and depression, anxiety, and stress. The finding that belief in God was linearly related to depression but curvilinearly related to anxiety highlights the importance of examining both models for each domain of psychological distress. These results suggest that belief in God may reduce depression, regardless of the certainty of that belief, whereas certainty of the belief may be more pertinent than the belief itself for anxiety. Consistent with our findings, other studies have demonstrated distinct relationships between aspects of religiosity and anxiety and depression (Koenig 2012; Peres et al. 2018). It may be that having any amount of belief in God reduces depressive symptoms through associated meaning (Peres et al. 2018), coping (Pargament et al. 1988), cognitive reappraisal (Vishkin et al. 2016), and comfort from God (Exline et al. 2000). These resources may uniquely reduce depression, although not anxiety to the same extent. Instead, the individuals with greater certainty in their belief or disbelief in God may have more clarity on how to respond to stressors, which ultimately reduces their overall levels of anxiety.

The current study has several limitations. The cross-sectional design precludes any causal claims about these pathways; for example, while there is theoretical support for the model that belief in God improves meaning in life, which then reduces depression severity (Park 2007), it may also be the case that depression reduces meaning in life, which then impacts one's belief in God. With that being said, these findings may serve as a launching point for future longitudinal studies to evaluate the underlying mediating pathways that link belief in God and depression, and to examine the directionality of these relationships. Another limitation of this study is that the potential responses to the question about belief in God (e.g., "I don't know if there is a personal God, but I do believe in a higher power 
of some kind") could be interpreted as capturing separate categories of belief, rather than a dimensional measurement of belief in God. It is unclear whether or not the scale of measurement for these responses would map onto a pure belief in God response set. With that being said, the extreme ends of this scale reflect the certainty in God's existence or non-existence, and the responses in between those extremes reflect less certainty in God's existence. Therefore, it seems likely that our findings captured some degree of a dimensional, rather than categorical, approach to belief in God. Additionally, the findings from the current study did not control for type 1 error rates, meaning there is a chance that false positives occurred. However, rather than risking false negatives in an area of research that has not been previously explored, the current study, instead, provides an initial launching point to rigorously test the pathways between belief in God and mental health using longitudinal designs. Finally, our sample consisted of college students at a single university at a single point in time, meaning the current findings may not generalize to other populations.

Future work should further explore the identified mediating variables to better characterize the relationships between belief in God and depression. Furthermore, given that the current study specifically evaluated this relationship based on belief in a single all-powerful being (i.e., "God"), further studies should examine whether these effects generalize to other populations who may believe in multiple gods or have different conceptualizations of god. Additionally, since the current study evaluated these relationships in a population with a relatively low risk of stigma surrounding disbelief in God, research is needed to examine whether these findings would replicate in populations with a higher risk of stigmatization.

\section{Conclusions}

The present study advances our understanding of the multiple ways that religious beliefs may influence mental health, adding useful evidence to the longstanding debate regarding religion's effects on mental health (AbdAleati et al. 2016; Freud [1907] 1959; Marx 1970; Moreira-Almeida et al. 2006; Park et al. 2019). Our findings suggest that the answers to this debate are more complex and qualified than might have originally been theorized. Our findings provide many promising avenues for future investigations to expand this more complex landscape of relationships. This study demonstrates the importance of examining both linear and curvilinear models when exploring the relationships between religious beliefs and different domains of psychological distress. Future work is needed to examine the models of these associations with a broader array of mental health variables. Additionally, future work should build on the present findings regarding the mediators underlying the relationship between belief in God and mental health.

Author Contributions: Conceptualization, Z.E.M., A.B.D., L.M.C. and C.L.P.; methodology, Z.E.M. and C.L.P.; formal analysis, Z.E.M.; investigation, L.M.C., I.A.G. and L.S.G.; data curation, Z.E.M.; writing - original draft preparation, Z.E.M., A.B.D., L.M.C. and C.L.P.; writing—review and editing, I.A.G. and L.S.G.; visualization, Z.E.M.; supervision, C.L.P. All authors have read and agreed to the published version of the manuscript.

Funding: This research received no external funding.

Institutional Review Board Statement: The study was conducted according to the guidelines of the Declaration of Helsinki and approved by the Institutional Review Board of University of Connecticut (X17-029; 22 February 2017).

Informed Consent Statement: Informed consent was obtained from all subjects involved in the study.

Data Availability Statement: The data presented in this study are available on request from the corresponding author.

Acknowledgments: The authors would like to thank the participants for their contributions to this study.

Conflicts of Interest: The authors declare no conflict of interest. 


\section{References}

AbdAleati, Naziha S., Nozarina Mohd Zaharim, and Yasmin Othman Mydin. 2016. Religiousness and mental health: Systematic review study. Journal of Religion and Health 55: 1929-37. [CrossRef] [PubMed]

Ashouri, Fazilat Pour, Hosein Hamadiyan, Mohammad Nafisi, Afshin Parvizpanah, and Sepehr Rasekhi. 2016. The relationships between religion/spirituality and mental and physical health: A review. Disease and Diagnosis 5: 28-34.

Austin, D., and Christopher John Lennings. 1993. Grief and religious belief: Does belief moderate depression? Death Studies 17: 487-96. [CrossRef]

Bosco-Ruggiero, Stephanie A. 2020. The relationship between Americans' spiritual/religious beliefs and behaviors and mental health: New evidence from the 2016 General Social Survey. Journal of Spirituality in Mental Health 22: 30-48. [CrossRef]

Bowman, Nicholas A., Alyssa N. Rockenbach, Matthew J. Mayhew, Tiffani A. Riggers-Piehl, and Tara D. Hudson. 2017. College students' appreciative attitudes toward atheists. Research in Higher Education 58: 98-118. [CrossRef]

Bush, Amber L., John P. Jameson, Terri Barrera, Laura L. Phillips, Natascha Lachner, Gina Evans, Ajani D.Jackson, and Melinda A. Stanley. 2012. An evaluation of the brief multidimensional measure of religiousness/spirituality in older patients with prior depression or anxiety. Mental Health, Religion \& Culture 15: 191-203. [CrossRef]

Carney, Lauren M., Crystal L. Park, and Ian A. Gutierrez. 2020. Religious beliefs and well-being and distress in congestive heart failure patients. Journal of Behavioral Medicine 43: 437-47. [CrossRef]

Cranney, Stephen. 2013. Do people who believe in God report more meaning in their lives? The existential effects of belief. Journal for the Scientific Study of Religion 52: 638-46. [CrossRef]

Doane, Michael J., and Marta Elliott. 2015. Perceptions of discrimination among atheists: Consequences for atheist identification, psychological and physical well-being. Psychology of Religion and Spirituality 7: 130-41. [CrossRef]

Doane, Michael J., Marta Elliott, and Portia S. Dyrenforth. 2014. Extrinsic religious orientation and well-being: Is their negative association real or spurious? Review of Religious Research 56: 45-60. [CrossRef]

Dolcos, Florin, Kelly Hohl, Yifan Hu, and Sanda Dolcos. 2021. Religiosity and resilience: Cognitive reappraisal and coping self-efficacy mediate the link between religious coping and well-being. Journal of Religion and Health. [CrossRef]

Edgell, Penny, Joseph Gerteis, and Douglas Hartmann. 2006. Atheists As "Other": Moral boundaries and cultural membership in American society. American Sociological Review 71: 211-34. [CrossRef]

Exline, Julie Juola, Ann Marie Yali, and William C. Sanderson. 2000. Guilt, discord, and alienation: The role of religious strain in depression and suicidality. Journal of Clinical Psychology 56: 1481-96. [CrossRef]

Exline, Julie J., Todd W. Hall, Kenneth I. Pargament, and Valencia A. Harriott. 2017. Predictors of growth from spiritual struggle among Christian undergraduates: Religious coping and perceptions of helpful action by God are both important. The Journal of Positive Psychology 12: 501-8. [CrossRef]

Farias, Miguel, and Anna-Kaisa Newheiser. 2019. The effects of belief in God and science on acute stress. Psychology of Consciousness: Theory, Research, and Practice 6: 214-23. [CrossRef]

Fetzer Institute/National Institute on Aging Working Group. 1999. Multidimensional Measurement of Religiousness/Spirituality for Use in Health Research. Kalamazoo: The Fetzer Institute, Available online: http:/ / fetzer.org/resources/multidimensional-measurementreligiousnessspirituality-use-health-research (accessed on 26 June 2021).

Freud, Sigmund. 1959. Obsessive actions and religious practices. In The Standard Edition of the Complete Psychological Works of Sigmund Freud, Volume IX (1906-1908): Jensen's 'Gradiva'and Other Works. London: Hogarth Press, pp. 115-28. First published 1907.

Galen, Luke William, and James D. Kloet. 2011. Mental well-being in the religious and the non-religious: Evidence for a curvilinear relationship. Mental Health, Religion E Culture 14: 673-89. [CrossRef]

Gall, Terry Lynn, and Manal Guirguis-Younger. 2013. Religious and spiritual coping: Current theory and research. In APA handbook of Psychology, Religion, and Spirituality (Vol 1): Context, Theory, and Research. Washington, DC: American Psychological Association, pp. 349-64. [CrossRef]

Gervais, Will M., and Maxine B. Najle. 2018. How many Atheists are there? Social Psychological and Personality Science 9: 3-10. [CrossRef]

Hammer, Joseph, Ryan Cragun, Karen Hwang, and Jesse Smith. 2012. Forms, frequency, and correlates of perceived anti-Atheist discrimination. Secularism and Nonreligion 1: 43-67. [CrossRef]

Harper, Marcel. 2007. The stereotyping of nonreligious people by religious students: Contents and subtypes. Journal for the Scientific Study of Religion 46: 539-52. [CrossRef]

Henry, Julie D., and John R. Crawford. 2005. The short-form version of the Depression Anxiety Stress Scales (DASS-21): Construct validity and normative data in a large non-clinical sample. The British Journal of Clinical Psychology 44, Pt 2: 227-39. [CrossRef]

Hirsh, Jacob B., Raymond A. Mar, and Jordan B. Peterson. 2012. Psychological entropy: A framework for understanding uncertaintyrelated anxiety. Psychological Review 119: 304-20. [CrossRef]

Horning, Sheena M., Hasker P. Davis, Michael Stirrat, and R. Elisabeth Cornwell. 2011. Atheistic, agnostic, and religious older adults on well-being and coping behaviors. Journal of Aging Studies 25: 177-88. [CrossRef]

James, William. 1958. The Varieties of Religious Experience: A Study in Human Nature. New York: New American Library. First published 1902.

Jiang, Xiao-Rong, Juan-Juan Du, and Rui-Yuan Dong. 2017. Coping style, job burnout and mental health of university teachers of the millennial generation. Eurasia Journal of Mathematics, Science and Technology Education 13: 3379-92. [CrossRef] 
Koenig, Harold G. 2009. Research on religion, spirituality, and mental health: A review. Canadian Journal of Psychiatry. Revue Canadienne De Psychiatrie 54: 283-91. [CrossRef]

Koenig, Harold G. 2012. Religion, spirituality, and health: The research and clinical implications. ISRN Psychiatry 2012: 278730. [CrossRef] [PubMed]

Krause, Neal. 2006. Religious doubt and psychological well-being: A longitudinal investigation. Review of Religious Research 47: $287-302$.

Marx, Karl. 1970. Critique of Hegel's 'Philosophy of Right'. Edited and Translated by Annette Jolin and Joseph O'Malley. Cambridge: Cambridge University Press.

McNulty, Kristy, Hanoch Livneh, and Lisa M. Wilson. 2004. Perceived uncertainty, spiritual well-being, and psychosocial adaptation in individuals with multiple sclerosis. Rehabilitation Psychology 49: 91-99. [CrossRef]

Moreira-Almeida, Alexander, Francisco Lotufo Neto, and Harold G. Koenig. 2006. Religiousness and mental health: A review. Brazilian Journal of Psychiatry 28: 242-50. [CrossRef] [PubMed]

Moscati, Arden, and Briana Mezuk. 2014. Losing faith and finding religion: Religiosity over the life course and substance use and abuse. Drug and Alcohol Dependence 136: 127-34. [CrossRef]

Murphy, Patricia E., and George Fitchett. 2009. Belief in a concerned god predicts response to treatment for adults with clinical depression. Journal of Clinical Psychology 65: 1000-8. [CrossRef]

Pargament, Kenneth I., Joseph Kennell, William Hathaway, Nancy Grevengoed, Jon Newman, and Wendy Jones. 1988. Religion and the problem-solving process: Three styles of coping. Journal for the Scientific Study of Religion 27: 90-104. [CrossRef]

Pargament, Kenneth, Margaret Feuille, and Donna Burdzy. 2011. The Brief RCOPE: Current psychometric status of a short measure of religious coping. Religions 2: 51-76. [CrossRef]

Park, Crystal L. 2007. Religiousness/spirituality and health: A meaning systems perspective. Journal of Behavioral Medicine 30: 319-28. [CrossRef] [PubMed]

Park, Crystal L., Lucy Finkelstein-Fox, Shane J. Sacco, Tosca D. Braun, and Sara Lazar. 2021. How does yoga reduce stress? A clinical trial testing psychological mechanisms. Stress and Health 37: 116-26. [CrossRef] [PubMed]

Park, Han Nah, Sara E. LePine, Kaye Cook, and Catherine Steininger. 2019. Do Nonreligious Individuals Have the Same Mental Health and Well-Being Benefits as Religious Individuals? Journal of Psychology \& Christianity 38: 81-99.

Paterson, Joanna, and Andrew James Peter Francis. 2017. Influence of religiosity on self-reported response to psychological therapies. Mental Health, Religion $\mathcal{E}$ Culture 20: 428-48. [CrossRef]

Peres, Mario Fernando Prieto, Helder H. Kamei, Patricia R. Tobo, and Giancarlo Lucchetti. 2018. Mechanisms behind religiosity and spirituality's effect on mental health, quality of life and well-being. Journal of Religion and Health 57: 1842-55. [CrossRef] [PubMed]

Pew Research Center. n.d. Religion in America: U.S. Religious Data, Demographics and Statistics. Pew Research Center's Religion \& Public Life Project. Available online: https:/ / www.pewforum.org/religious-landscape-study/ (accessed on 20 May 2021).

Rasic, Daniel, Steve Kisely, and Donald B. Langille. 2011. Protective associations of importance of religion and frequency of service attendance with depression risk, suicidal behaviours and substance use in adolescents in Nova Scotia, Canada. Journal of Affective Disorders 132: 389-95. [CrossRef] [PubMed]

Rohrbaugh, John, and Richard Jessor. 1975. Religiosity in youth: A personal control against deviant behavior? Journal of Personality 43: 136-55. [CrossRef]

Ronneberg, Corina R., Edward Alan Miller, Elizabeth Dugan, and Frank Porell. 2016. The protective effects of religiosity on depression: A 2-Year prospective study. The Gerontologist 56: 421-31. [CrossRef]

Rosmarin, David H., Joseph S. Bigda-Peyton, Sarah J. Kertz, Nasya Smith, Scott L. Rauch, and Thröstur Björgvinsson. 2013. A test of faith in God and treatment: The relationship of belief in God to psychiatric treatment outcomes. Journal of Affective Disorders 146: 441-46. [CrossRef]

Rosseel, Yves. 2012. lavaan: An R package for structural equation modeling. Journal of Statistical Software 48: 1-36. [CrossRef]

Schnitker, Sarah A., Benjamin Houltberg, William Dyrness, and Nanyamka Redmond. 2017. The virtue of patience, spirituality, and suffering: Integrating lessons from positive psychology, psychology of religion, and Christian theology. Psychology of Religion and Spirituality 9: 264-75. [CrossRef]

Silton, Nava, Kevin Flannelly, Kathleen Galek, and Christopher Ellison. 2013. Beliefs about God and mental health among American adults. Journal of Religion and Health 53: 1285-96. [CrossRef]

Steger, Michael F., and Patricia Frazier. 2005. Meaning in life: One link in the chain from religiousness to well-being. Journal of Counseling Psychology 52: 574-82. [CrossRef]

Sternthal, Michelle J., David R. Williams, Marc A. Musick, and Anna C. Buck. 2010. Depression, anxiety, and religious Life: A search for mediators. Journal of Health and Social Behavior 51: 343-59. [CrossRef] [PubMed]

Tran, Christy T., Eric Kuhn, Robyn D. Walser, and Kent D. Drescher. 2012. The relationship between religiosity, PTSD, and depressive symptoms in veterans in PTSD residential treatment. Journal of Psychology and Theology 40: 313-22. [CrossRef]

Vandekerckhove, Joachim, Dora Matzke, and Eric-Jan Wagenmakers. 2015. Model Comparison and the Principle of Parsimony. Edited by Jerome R. Busemeyer, Zheng Wang, James T. Townsend and Ami Eidels. Oxford: Oxford University Press, vol. 1. [CrossRef]

Vishkin, Allon, Yochanan E. Bigman, Roni Porat, Nevin Solak, Eran Halperin, and Maya Tamir. 2016. God rest our hearts: Religiosity and cognitive reappraisal. Emotion 16: 252-62. [CrossRef] 
Wilkinson, Peter J., and Peter G. Coleman. 2010. Strong beliefs and coping in old age: A case-based comparison of atheism and religious faith. Ageing $\mathcal{E}$ Society 30: 337-61. [CrossRef]

Wood, Benjamin T., Everett L. Worthington Jr., Julie Juola Exline, Ann Marie Yali, Jamie D. Aten, and Mark R. McMinn. 2010. Development, refinement, and psychometric properties of the Attitudes Toward God Scale (ATGS-9). Psychology of Religion and Spirituality 2: 148-67. [CrossRef] 